\title{
Health Benefits of Staying Active After Retirement
}

\author{
Hyunsook Kang ${ }^{1} \&$ Mihae Bae ${ }^{2}$ \\ ${ }^{1}$ School of Human Sciences, Stephen F. Austin State University \\ ${ }^{2}$ Department of Kinesiology and Health Science, Stephen F. Austin State University \\ Correspondence: Hyunsook Kang, School of Human Sciences, Stephen F. Austin State University
}

Received: October 10, 2020 Accepted: November 16, 2020 Online Published: November 23, 2020

doi:10.5539/res.v12n4p43

URL: https://doi.org/10.5539/res.v12n4p43

\begin{abstract}
The objective of this study was to examine the breadth and depth of relationships with retirement and health regarding older adults' physical activities. In addition, the possible implication of the relationships is to examine better understanding of how to stay active after retirement. Data from the American Association of Retirement Persons (AARP, Montenegro, 2015) telephone survey were used, which sampled persons, age range was 60-89 years old ( $\mathrm{n}=134)$. Result indicated that health and physical activity factors affected retired older life satisfaction. It is not surprising that retired older adults are less satisfied when they have decreased physical health, but more satisfied when they engage in diverse physical activities or exercise after retirement (USDHHS, 2018). Given that aerobic and muscle strengthening activities contributed to improving physical function and reducing the risk of falls (Chodzko-Zajko et al., 2009; Spark et al., 2018), this study also supported the findings that aerobic and muscle strengthening activities with relative intensity level positively influenced the satisfaction levels of participants (USDHHS, 2018).
\end{abstract}

Keywords: retirement, older adults, physical activities, health

\section{Introduction}

Life expectancy across the world has dramatically increased since the early $20^{\text {th }}$ century. World Health Organization (WHO) estimates that a global average life expectancy is approximately 72 years. In the United State, life expectancy is 78.6 years (Arias \& Xu, 2019) According to Centers for Disease Control and Prevention (2019), six out of ten adults have a chronic disease and four in ten have two or more in the United States. Multimorbidity is common in older adults Research has shown that the participation in physical activities can lower the risk of chronic diseases and also improve physical and cognitive functions for older adults (McPhee et al., 2016; USDHHS, 2018). People are becoming more interested and investing in health and health related issues including physical activities and exercise in order to improve the quality of their lives.

Older people generally decrease in the participation in regular physical activities and increase in sedentary time (McPhee et al., 2016; Sparks et al., 2018). Retirement often precipitate this trend leading to adverse health outcomes. There is growing research about retirement and its influence on older adult's lives. Research suggested that retirement can be considered as one of a series of stages (Atchley, 2000) as it accompanies adjustment and the transitional process from work to retirement (Wang, 2007).

Retirement may affect the health and life style in later life. On the one hand, past research noted that retirement may be associated with health decline and decreased social network size (Leslie, George, \& Morrow-Howell, 2007; Virginia, 2006). Retirement may be associated with a loss of professional colleagues and work-related friends (Gloria et al, 2015). By contrast, growing numbers of older adults may maintain their active participation in social networks through diverse physical activities including daily exercise after their retirement (Hooyman \& Kiyak, 2018; Thompson \& Whearty, 2004). Compared to working adults, retired older adults may have a greater amount of time to be involved in diverse physical activities (Virginia, 2006). Given that aging processes encompass social, emotional, and physical changes or adaptations, it is clear that aging can be considered as not only a physical but also a social process (Nussbaum, Pecchioni, Robinson, \& Thompson, 2000).

Given that retirement is viewed as a transitional life process, the majority of older adults will experience positive adaptation within their individual, family, and societal contexts (Gardiner, Stuart, Forde, Greenwood, MacKenzie, \& Perrett, 2007). Therefore, it is important to find to what extent retirement affects life style, such as physical activities. Although much previous research has noted older adults' social life, few findings have been found regarding the relationships between older adults' retirement status, health factor, and physical activities in later life. For example, 
physical activities changes may be associated with changes in levels of health as retirement may require adjustment to new life patterns. However, it still remains uncertain whether older adults' life satisfaction is influenced by retirement and health factors or not. If so, it is still not clear how much the factors can account for the retired older adults' life satisfaction. Therefore, further research will be needed to provide an accurate picture of the dynamics of the retirement status, health, and demographic differences in physical activities and life satisfaction in later life.

\section{Literature Review}

Pinquart and Schindler (2007) noted that retirement entails older adults' adaptation for changing life contexts (e.g., decrease in income, decline in physical health). In the longitudinal study of Wang (2007), retirement adjustment and psychological well-being were influenced by contextual variables (e.g., marital status, health, and retirement planning). Wang (2007) examined retired adults who were 51-61 years old and their social networks. Growth mixture modeling (GMM) revealed that among retired adults, contextual resources (marital status, bridge job) had a mediator effect on adjustment to retirement. Specifically, Wang (2007) found that retired older adults do not necessarily follow a uniform adjustment pattern. Rather, retirement adjustment varies with individual and social resources. Therefore, it is possible that retirement may cause changes in daily life patterns, social relationships, and health and income status (Pinquart \& Schindler, 2007), but can also result in ample benefits to and consistency within older adults' social networks. For example, through actively participating in physical activities and health related-activities (Beck, 2000), it is possible to build self-esteem and health for retired older adults. Indeed, retired older adults may enhance health through physical active engagement (Quadagno, 2002).

Recently, there has been growing agreement that the role of leisure activities is increasingly important for retired older adults. Retired older adults are more likely to have a free time for spending time with family and friends and engaging in leisure, travel, sport, religious, cultural, and educational activities (Hooyman \& Kiyak 2018). Having adequate leisure activities may decrease the negative aspects associated with retirement such as emotional distress, anxiety from financial instability, or health decline. Furthermore, participation in leisure activities may provide a sense of relief after retirement (Quadagno, 2002).

Given that retirement status changes in later life may have a significant influence on older adults' health and well-being and their increased life expectancy after retirement, it is necessary to better understand about the changes of retirement status and their influence on health in later life. In addition, given that the sizable baby boomer generation is growing in age, a better understanding of how the changes affect older adults' health and life satisfaction is urgent. By understanding the associations, it is possible to make social policy and ultimately bolster the social support systems of older adults. In addition, reflecting on the increasing number of retired older population in the future, this study will contribute to an understanding of the influence of health status, and diverse demographic differences (e.g., gender, income, race, age) on older adults' physical activities. Therefore, if older adults prepare for retirement and have retirement plans prior to retirement, adjustment is more likely to be a gradual satisfactory adaptation without dramatic changes in life satisfaction.

\section{Research Question}

Thus, the present study addressed the following research question: To what extent do physical activities contribute to the life satisfaction of retired older adults?

\section{Method}

Sample: A secondary data analysis from a national AARP (telephone) survey of adults (Montenegro, 2015).

Age range: $60-89$ years old widows $(n=134)$

Race/Ethnicity: White ( $\mathrm{n}=306)$, Black ( $\mathrm{n}=119)$, Hispanic $(\mathrm{n}=209)$

Measures:

Life satisfaction. Life satisfaction was assessed with a single-item Likert scale question (1= "strongly unsatisfied", 10= "very satisfied").

Sample item: "On which of these 10 steps of the ladder do you feel you personally stand at the present time?"

Demographics. Demographics (e.g., age, gender, ethnicity) were assessed via single-item questions.

Physical/Mental health was measured with a self-reported Likert type scale (1= "poor", $2=$ "fair", $3=$ "good", $4=$ "very good", $5=$ "excellent"). The mean score of physical health was $3.2(S D=1.1)$ and a higher score reflected the higher level of health.

A dummy variable of retirement status was coded ( $0=$ "no, $1=$ "yes").

Physical Activities. Physical activities were assessed via single item questions on frequency of physical activities behaviors (1="never", 4="often"). 
Sample item: "For each of these activities, please check whether it is something you do often, occasionally, not very often, or never":

$\begin{array}{lccr}\text { Walking } & \text { Gardening } & \text { Yoga } & \\ \text { Dancing } & \text { Swimming } & \text { Running } & \\ \text { Play at the park } & \text { Play with pets } & \text { Biking } & \text { Other }\end{array}$

\section{Results}

To address the research question, a two-step hierarchical regression was conducted. In the first step, satisfaction was regressed on the health factors. Collectively, the factors accounted for $21 \%$ variance in life satisfaction $\left(R^{2}\right.$ adjusted $=.18$, $p<.001)$. Beta values indicated that health status was a unique predictor.

In the second step, the leisure factors were added to the regression equation. There was a $10 \%$ increase in satisfaction variance (total $R^{2}=.31, p<.001$, total

$R^{2}$ adjusted $=.23, p<.001$ ). Beta values indicated that (a) Walking, (b) Yoga, (c) Dancing (d) Swimming (e) Running, and (f) Biking were unique predictors.

Table 1. Regression of life satisfaction on retirement and physical activities factors

\begin{tabular}{ccccc}
\hline Step 1 - Health Factors $\left(R^{2}=.21, p<.001\right)$ & B & SE & $B$ \\
\hline Disability & & & & \\
Stress & -.35 & .53 & -.06 \\
Depression & -.10 & .15 & -.06 \\
Health status & -1.01 & .48 & $-.19^{*}$ \\
& .64 & .36 & $.15^{*}$
\end{tabular}

\begin{tabular}{llll} 
Step 2- Leisure Factors & $\left(R^{2}\right.$ change $\left.=.10, p<.001\right)$ & & \\
Walking & .07 & .28 & $.03^{* *}$ \\
Gardening & .63 & .31 & .19 \\
Dancing & .28 & .27 & $.11^{*}$ \\
Swimming & .15 & .26 & $.06^{*}$ \\
Biking & .50 & .30 & $.15^{*}$ \\
Play at the park & .60 & .26 & .24 \\
Play with pets & .16 & .20 & .08 \\
Yoga & .30 & .29 & $.11^{* *}$ \\
Running & .26 & .23 & $.11^{*}$ \\
Other & .17 & .31 & .06 \\
\hline
\end{tabular}

(Total $\left.R^{2}=.31, p<.001\right) \quad * p<.05 \quad * * * p<.001$

\section{Conclusion and Discussion}

The results indicated that health and physical activity factors affected retired older life satisfaction. It is not surprising that retired older adults are less satisfied when they have decreased physical health, but more satisfied when they engage in diverse physical activities or exercise after retirement (USDHHS, 2018). Given that aerobic and muscle strengthening activities contributed to improving physical function and reducing the risk of falls (Chodzko-Zajko et al., 2009; Spark et al., 2018), this study also supported the findings that aerobic and muscle strengthening activities with relative intensity level positively influenced the satisfaction levels of participants (USDHHS, 2018). Prior research on older adults has supported the linkage of satisfaction to physical activity (Gloria et al, 2015). The results contrast research on satisfaction and depression (Koivumaa-Honkanen, Kaprio, Honkanen, Viinamaki, \& Koskenvuo, 2004).

It was somewhat surprising that Gardening, Play at the park, and Play with pets was not associated with satisfaction. Our results fit with Gloria et al.'s study (2015) in which retired older adults engaging in diverse physical and social actives are better coping in later life. It is possible that older adults have less or fewer outside activities experienced better adjustment in aging process. These findings suggested that the role of physical activities in later life may be more complex than previously presumed, and requires additional investigation. However, there is a contrasting study, which shows that older adults may undergo negative experiences such as health decline, depression, and lower level of life satisfaction after retirement (Kim \& Moen, 2002). For example, in the study of Adams, Sanders, and Auth (2004), psychological well being 
and their frequency of engaging in physical activities or exercise was examined. Regression analysis revealed that retired older adults participated less actively in physical activities reported higher levels of loneliness and depression and psychological well being (Adams et al., 2004).

It is understandable that engaging in physical activities is one way in which older adults cope with getting physical health decreasing (DHHS, 2019). More generally, there is ample correlational evidence that physical activity plays a significant role in the successful aging of older adults (Chodzko-Zajko et al., 2009; Jaumot-Pascual, Monteagudo, Kleiber, \& Cuenca, 2016; Spark et al., 2018). Physical activities can often be undervalued as a coping strategy, but it can have substantial ameliorative effects from depression and stress in later life (DHHS, 2019; Rodríguez, Fernández, \& Rojo, 2012). Therefore, it is possible to assume that engagement in physical activities is positively related to life satisfaction and physical/mental health (ACSM, 2019; DHHS, 2018; Lennartsson \& Silverstein, 2001). Similarly, Hooyman and Kiyak (2018) noted that older adults are likely to join in physical activities are positively related to their health and life satisfaction. In addition, exercise activities involvement is highly associated with new life adjustment for older adults. Despite these findings, little attention has been given to studies of leisure activities among older adults.

Given the previous research on retirement and retired older adults' changes in their life satisfaction and physical activities, the results may be more complex than previously presumed and additional investigation should be continued. For example, the current findings support the life course perspectives that older adults may maintain their social roles and in which they are able to adapt to their changing life contexts after retirement. Therefore, retirement may not cause dramatic physical changes in later life (Pinquart \& Schindler, 2007).

Similar to the life course perspective, the convoy model also supports the current findings, as older adults move in and out of physical activities over a life time, creating a pattern that will support adjustment to challenging life events such as retirement. However, the current study uses cross-sectional data in which it is impossible to examine any changes after retirement exactly. Further longitudinal research is necessary to find the nature and dynamic of retirement and its consequences on life satisfaction and physical activities. The results of this study will help researchers, gerontologists, and social policy makers who are interested in life satisfaction, physical activities, and health in later life. Furthermore, understanding the associations between retirement, health, and physical activities in later life will aid in understanding social dynamics in later life.

\section{References}

Arias, E., \& Xu, J. (2019). United States life Tables, 2017. National Vital Statistics Reports, 68(7), 1- 65.

Atwood, J. D., \& Genovese, F. (2006). Therapy with single parents: A social constructionist approach. Binghamton, NY: The Haworth Press.

Bennett, K. M., Smith, P. T., \& Hughes, G. M. (2005). Coping, depressive feelings and gender differences in late life widowhood. Aging \& Mental Health, 9, 348-353. https://doi.org/10.1080/13607860500089609

Bowling, A., Farquhar, M., \& Grundy, E. (1996). Associations with changes in life satisfaction among three samples of elderly people living at home. International Journal of Geriatric Psychiatry, 11, 1077-1087.

Centers for Disease Control and Prevention (2019). Chronic diseases in America, United State (http://www.cdc.gov/chronicdisease/resources)

Chodzko-Zajko, W. J., Proctor, D. N., Singh, M. F., Minson, C. T., Nigg, C. R., Salem, G. J., \& Skinner, J. S. (2009). Exercise and physical activity for older adults. Medicine \& Science in Sports and Exercise, 41(7), 1510-1530. https://doi.org/10.1249/MSS.0b013e3181a0c95c

Fernández-Mayoralas, G., Rojo-Pérez, F., Martínez-Martín, P., Prieto-Flores, M. E., Rodríguez-Blázquez, C., Martín-García, S., ... \& Forjaz, M. J. (2015). Active ageing and quality of life: factors associated with participation in leisure activities among institutionalized older adults, with and without dementia. Aging \& mental health, 19(11), 1031-1041. https://doi.org/10.1080/13607863.2014.996734

Grafanaki, S., Pearson, D., Cini, F., Godula, D., McKenzie, B., Nason, S., \& Anderegg, M. (2005). Sources of renewal: A qualitative study on the experience and role of leisure in the life of counsellors and psychologists. Counselling Psychology Quarterly, 18, 31-40. https://doi.org/10.1080/09515070500099660

Hamarat, E., Thompson, D., Zabrucky, K., Steele, D., Matheny, K., \& Aysan, F. (2001). Perceived stress and coping resource availability as predictors of life satisfaction in young, middle-aged, and older adults. Experimental Aging Research, 27, 181-196. https://doi.org/10.1080/036107301750074051

Hendricks, J., \& Cutler, S. J. (1990). Leisure and structure of our life worlds. Aging and Society, 10, 85-94. 
https://doi.org/10.1017/S0144686X00007868

Hooyman, N. R., \& Kiyak, H. A. (2018). Aging Matters: An introduction to Social Gerontology.

Jang, Y., Mortimer, J., Haley, W. E., \& Graves, A. M. (2004). The role of social engagement in life satisfaction: Its significance among older individuals with disease and disability. The Journal of Applied Gerontology, 23(3), 266-278. https://doi.org/10.1177/0733464804267579

Jaumot-Pascual, N., Monteagudo, M. J., Jleiber, D. A., \& Cuenca, J. (2016). Gender differences in meaningful leisure following major later life events. Journal of Leisure Research, 48(1), 83-103. https://doi.org/10.18666/jlr-2016-v48-i1-6244

Koivumaa-Honkanen, H., Kaprio, J., Honkanen, R., Viinamaki, H., \& Koskenvuo, M. (2004). Life satisfaction and depression in a 15-year follow-up study of healthy adults. Social Psychiatry and Psychiatric Epidemiology, 39, 994-999. https://doi.org/10.1007/s00127-004-0833-6

Lamme, S., Dykstra, P. A., \& van Groenou, M. B. (1996). Rebuilding the network: New relationships in widowhood. Personal Relationships, 3, 337-349. https://doi.org/10.1111/j.1475-6811.1996.tb00120.x

La Veist, T. A., Sellers, R. M., Brown, K. A., \& Nickerson, K. J. (1997). Extreme social isolation, use of community-based senior support services, and mortality among African American elderly women. American Journal of Community Psychology, 25, 721-732. https://doi.org/10.1023/A:1024643118894

Lee, C. D., \& Bakk, L. (2001). Later-life transitions into widowhood. Journal of Gerontological Social Work, 35(3), 51-63. https://doi.org/10.1300/J083v35n03_05

Lennartsson, C., \& Silverstein, M. (2001). Does engagement with life enhance survival of elderly people in Sweden? The role of social and leisure activities. Journal of Gerontology: Social Science, 56B(6), S335-342. https://doi.org/10.1093/geronb/56.6.S335

Lopata, H. Z. (1996). Current widowhood: Myths and realities. Thousand Oaks, CA: Sage Publications.

McPhee, J. S., French, D. P., Jackson, D., Nazroo, J., Pendleton, N., \& Degens, H. (2016). Physical activity in older age: perspectives for healthy aging and fragility. Biogerontology, 17(3), 567-580. https://doi.org/10.1007/s10522-016-9641-0

Montenegro, X. (2003). Lifestyles, dating and romance: A study of midlife singles. Washington, DC: American Association of Retired Persons Publications.

Oishi, S., Diener, E., Suh, E., \& Lucas, R. E. (1999). Value as a moderator in subjective well-being. Journal of Personality, 67, 157-184. https://doi.org/10.1111/1467-6494.00051

Pagano, I. S., Barkhoff, H., Heiby, E. M., \& Schlicht, W. (2006). Dynamical modeling of the relations between leisure activities and health indicators. Journal of Leisure Research, 38, 61-77. https://doi.org/10.1080/00222216.2006.11950069

Patterson, I. (1996). Participation in leisure activities by older adults after a stressful life event: The loss of a spouse. International Journal of Aging and Human Development, 42, 123-142. https://doi.org/10.2190/TG1M-75CB-PL27-R6G3

Pellman, J. (1992). Widowhood in elderly women: Exploring its relationship to community integration, hassles, stress, social support, and social support seeking. Journal of Aging and Human Development, 35, 253-264. https://doi.org/10.2190/L316-1XQE-9F79-UX4D

Rodríguez, V., Fernández, G., \& Rojo, F. (2012). Actividades de ocio y participación como base de una vejez activa. In D. Ramiro (Ed.), Una Vejez Activa en España. Informe del Grupo de Población del CSIC (pp. 53-80). Madrid: EDIMSA Editores Médicos, S.A.

Sparks, J. R., Breneman, C. B., Parter, R. R., Blair, S. N., \& Wang, X. F. (2018). Effects of a 16-week treadmill exercise on physical activity and sedentary time in older women. Medicine and Science in Sports \& Exercise, 50, 714. https://doi.org/10.1249/01.mss.0000538354.89620.84

Stevens-Ratchford, R., \& Krause, A. (2004). Visually impaired older adults and home-based leisure activities: The effects of person-environment congruence. Journal of Visual Impairment \& Blindness, 98, 14-27. https://doi.org/10.1177/0145482X0409800103

Ungar, L., \& Florian, V. (2004). What helps middle-aged widows with their psychological and social adaptation several years after their loss? Death Studies, 28, 621-642. https://doi.org/10.1080/07481180490476434

US Department of Health and Human Services. (2018). Physical activity guidelines for Americans ( $2^{\text {nd }}$ edition). 
Washington D.C., US Government Printing Office.

van Baarsen, B., \& van Groenou, M. B. (2001). Partner loss in later life: Gender differences in coping shortly after bereavement. Journal of Loss and Trauma, 6, 243-262. https://doi.org/10.1080/108114401753201688

World Health Organization. (2018). World Health Statistics 2016: Monitoring health for the Sustainable Development Goals (SDGs). Geneva, Switzerland.

\section{Copyrights}

Copyright for this article is retained by the author(s), with first publication rights granted to the journal.

This is an open-access article distributed under the terms and conditions of the Creative Commons Attribution license (http://creativecommons.org/licenses/by/4.0/). 